\title{
Simple linear algorithm to estimate the space-time variability of precipitable water in the Araucanía Region, Chile
}

\author{
L. Morales-Salinas ${ }^{1 *}$, J.C. Parra-Aravena ${ }^{2,3}$, F. Lang-Tasso ${ }^{1}$, R. Abarca-Del Río ${ }^{4}$, \\ E. Jorquera-Fontena ${ }^{5}$ \\ ${ }^{1}$ Departament of Environmental Sciences and Renewable Natural Resources, Faculty of Agronomic Sciences, \\ Universidad de Chile. P.O. Box 1004, La Pintana, Santiago. ${ }^{2}$ Department of Physical Sciences, Faculty of \\ Engineering, Sciences and Administration, Universidad de La Frontera, Casilla 54-D, Temuco, Chile. ${ }^{3}$ Center \\ for Optics and Photonics, Universidad de Concepción, Casilla 4016, Concepción, Chile. ${ }^{4}$ Departament of \\ Geophysics, Faculty of Physical and Mathematical Sciences, Universidad de Concepción, P.O. Box 160-C, \\ Concepción, Chile. ${ }^{5}$ Doctorate Programme in Natural Resources Sciences. Universidad de La Frontera. Casilla \\ 54-D, Temuco, Chile. ${ }^{*}$ Corresponding author:lmorales@renare.uchile.cl
}

\begin{abstract}
This work proposes a linear algorithm which relates precipitable water (PW) with altitude and distance from the coast, on a regional scale. For precipitable water, the ERA-Interim (ECMWF) database for the period 1989-2010 was used, while a digital elevation model was used for the geographical variables. The results obtained indicate statistical significance between the two variables $(p<0.01)$, with a confidence level of $99 \%$. The model makes it possible to describe the mean monthly space-time variability of precipitable water, stratifying the study area into clearly differentiated zones.
\end{abstract}

Keywords: linear algorithm, precipitable water, digital elevation model. 


\section{Introduction}

Atmospheric water vapour is the principal contributor to the greenhouse effect and plays a key role in our understanding of the Earth's climate. Precipitable water (PW) is the amount of vertically integrated water vapour and can be expressed in $\mathrm{g} \mathrm{cm}^{-2}$, or as the height of an equivalent column of liquid water in $\mathrm{cm}$. Traditionally, there have been three atmospheric water vapour observing systems on a global scale: radio soundings, general circulation models and satellite observations. PW is an important component of the hydrological cycle and is adopted as an input variable in global climatological studies. Moreover, it has the potential to support hydrological, biospheric and atmospheric modelling efforts, on both local and regional scales, since it is widely used in energy budget and evapotranspiration studies (Hadjimitsis et al., 2011). Furthermore, $\mathrm{PW}$ is an essential requirement in atmospheric correction of high spatial resolution satellite data, and it is also necessary for enhancing the precision of land surface temperature estimates obtained from satellite data (Wan, 1999; Morales et al., 2002; Morales and Parra, 2002; Parra et al., 2006; Vera et al., 2010).

One way of obtaining the PW is through radio soundings or database compilations, such as those extracted from Moderate Resolution Imaging Spectroradiometer (MODIS) and ERA-Interim, an ensemble of meteorological data based on the Reanalysis carried out by the European Centre for Medium-Range Weather Forecasts. ERA-Interim (Dee et al., 2011) considers information from 1 January 1989 to the present, and can be accessed on line (http://www. ecmwf.int/research/era/do/get/era-interim). The information is presented in the form of both daily and monthly average values, and covers the whole planet with a grid resolution of 1.5 degrees of latitude and longitude. For each node of the grid, profiles are available for temperature, pressure, specific humidity and other variables.

The objective of the present communication is to propose a simple linear algorithm for estimating and describing the monthly mean space-time variability of precipitable water, on a regional scale, based on the geographical characteristics of the observation point.

\section{Materials and methods}

\subsection{Study area}

The study area is the Araucanía Region, Chile (Figure 1), with a total area of $31,840.3 \mathrm{~km}^{2}$. The study area presents two well differentiated climatic characteristics. The northern part of the Region has a warm temperate climate with a short dry season (less than 4 months), while the part lying to the south of latitude $-38^{\circ}$ is associated with a wet temperate climate, with Mediterranean influence. The Region presents distinct geographical units: coastal plain, coastal mountain range, central depression, Andean pre-cordillera and Andes Mountains, with average altitudes varying between 200 and 2,000 m.a.s.l. 


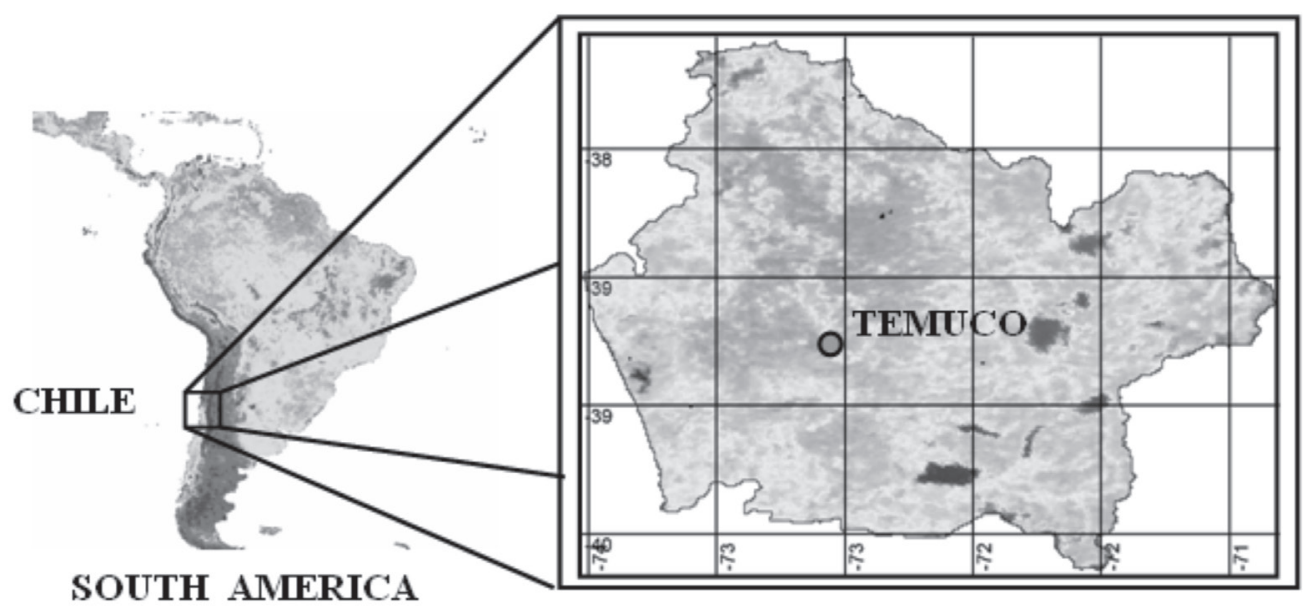

Figure 1. Study area: Araucanía Region, Chile.

\subsection{Precipitable water}

For this study, the average monthly precipitable water values were obtained from data supplied by ERA-Interim for the period 1989-2010. Considering that the grid resolution is around $166.5 \times 166.5 \mathrm{~km}$, the data were interpolated to bring them down to a resolution of $20 \times 20 \mathrm{~km}$, using kriging interpolation by blocks with a linear variogram. The interpolated information was used to apply downscaling (Fuentes et al., 2000; Wetterhall et al., 2007) to obtain the precipitable water vapour at a resolution of $1 \mathrm{~km} \mathrm{x} 1 \mathrm{~km}$, to coincide with the spatial resolution of one pixel of the NOAA satellite image. The following linear model is proposed for the parameterization of precipitable water as a function of geographical characteristics such as altitude and distance from the coast:

$$
P W=A+B \cdot A L T+C \cdot D I L+\gamma
$$

A, B and C are monthly mean coefficients depending on latitude and longitude; ALT is the altitude (m), DIL represents the distance from the coast $(\mathrm{m})$ and $g$ represents the error associated with estimation in $g$ $\mathrm{cm}^{-2}$. Equation 1 is founded because the amount of water vapour in the atmosphere is affected by temperature variations and depends on variations in altitude (ALT), and geographical conditions, such as distance to the Pacific Ocean (DIL) (AGU, 2002; Parwati et al, 2007). The application of the model assumes the use of a digital elevation model, with ALT as a variable. In this study we used GTOPO30 (http://edc.usgs.gov/ products/elevation/gtopo30/gtopo30.html), geo-referenced to the datum WGS84 (Figure 1).

\section{Results}

Table 1 shows, by month: regression coefficients A, B and $\mathrm{C}$; the coefficient of determination $\left(\mathrm{r}^{2}\right)$; the statistical significance $(\mathrm{p})$; and the standard error $\mathrm{g}$. It may be seen that the proposal of the algorithm to describe the relation between precipitable water, altitude and distance from the coast is significant. In fact, the statistical significance, on average $p<0.01$, indicates that the relation between the variables considered is statistically significant, with a confidence level of $99 \%$. 
The value of $r^{2}$ shows that the model used explains, on average, $83 \%$ of the variability in precipitable water vapour, representing a strong relationship between the variables.
The time variability of coefficients A, B and C of equation (1) for the Araucanía Region of Chile are shown in Figure 2.

Table 1. Values of coefficients A and B for the regression. $P W=A+B \cdot A L T+C \cdot D I L+\gamma$. The statistical values of the coefficient of determination, $\mathrm{r}^{2}$, standard error $\mathrm{g}$ and statistical significance, $\mathrm{p}$, are also indicated.

\begin{tabular}{lcccccc}
\hline Month & $\begin{array}{c}\mathbf{A} \\
\left(\mathbf{g ~ c m}^{-2}\right)\end{array}$ & $\begin{array}{c}\mathbf{B ~ x 1 0} \mathbf{- 5} \\
\left(\mathbf{g ~ c m}^{-2} \mathbf{~ m}^{-1}\right)\end{array}$ & $\begin{array}{c}\mathbf{C ~ x 1 0} \\
\left(\mathbf{g ~ c m}^{-2} \mathbf{~ m}^{-1}\right)\end{array}$ & $\begin{array}{c}\mathbf{g} \mathbf{~ x 1 0} \\
\left(\mathbf{g ~ c m}^{-2}\right)\end{array}$ & $\mathbf{r}^{\mathbf{2}}$ & $\mathbf{p}$ \\
\hline January & 1.53828 & 4.4402066 & -0.187775 & 6.6467 & 0.84 & 0.0000 \\
February & 1.56530 & 5.0148432 & -0.177534 & 7.0048 & 0.80 & 0.0000 \\
March & 1.57972 & 5.2872668 & -0.197890 & 7.4967 & 0.81 & 0.0000 \\
April & 1.43329 & 4.9759926 & -0.206196 & 7.3831 & 0.83 & 0.0000 \\
May & 1.38728 & 5.1646561 & -0.209144 & 7.5440 & 0.83 & 0.0000 \\
June & 1.31359 & 4.6527804 & -0.201236 & 7.3766 & 0.83 & 0.0000 \\
July & 1.16480 & 4.2493843 & -0.183105 & 6.5428 & 0.84 & 0.0000 \\
August & 1.17262 & 4.1886861 & -0.180572 & 6.3217 & 0.84 & 0.0000 \\
September & 1.12749 & 3.9161601 & -0.161547 & 5.8278 & 0.83 & 0.0000 \\
October & 1.21776 & 3.7382387 & -0.159670 & 5.7643 & 0.83 & 0.0000 \\
November & 1.34550 & 3.6931073 & -0.167441 & 5.9018 & 0.84 & 0.0000 \\
December & 1.50005 & 3.9896655 & -0.182630 & 6.3881 & 0.84 & 0.0000 \\
\hline
\end{tabular}

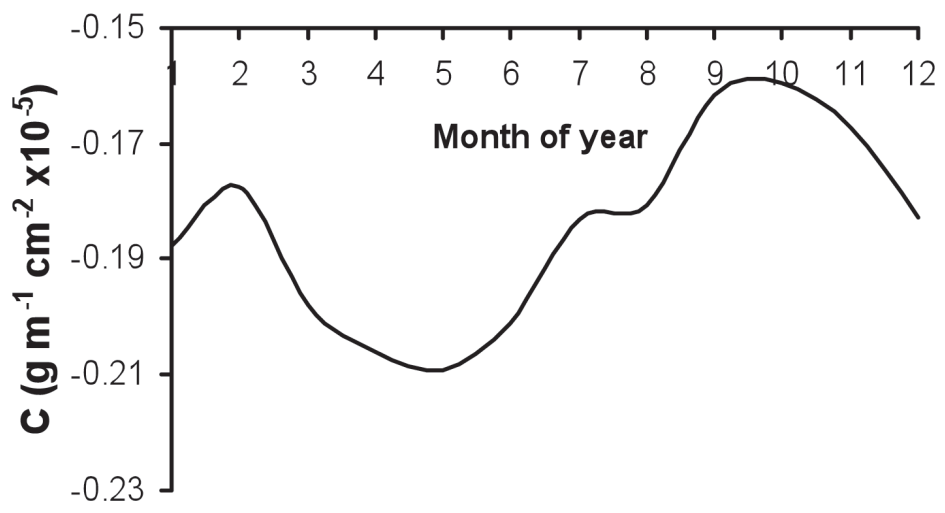

Figure 2. Time variability of coefficients $\mathrm{A}, \mathrm{B}$ and $\mathrm{C}$ of regression $W=A+B \cdot A L T+C \cdot D I L+\gamma$ in the Araucanía Region, Chile. 
In order to obtain categories with uniform values for $\mathrm{PW}$, a non-hierarchical cluster analysis was done using the minimum distance criterion (Perez, 2004). This technique allowed pixels with similar precipitable water vapour values to be considered in a single cluster, while pixels with different values were located in other clusters. Figure 3 shows the result of the clus- ter analysis carried out on the monthly mean values; it may be clearly observed that the precipitable water is stratified into different zones. These correspond to the coastal area, characterised by the Nahuelbuta coastal range; the central depression; the Andean pre-cordillera; and the Andes Mountains.

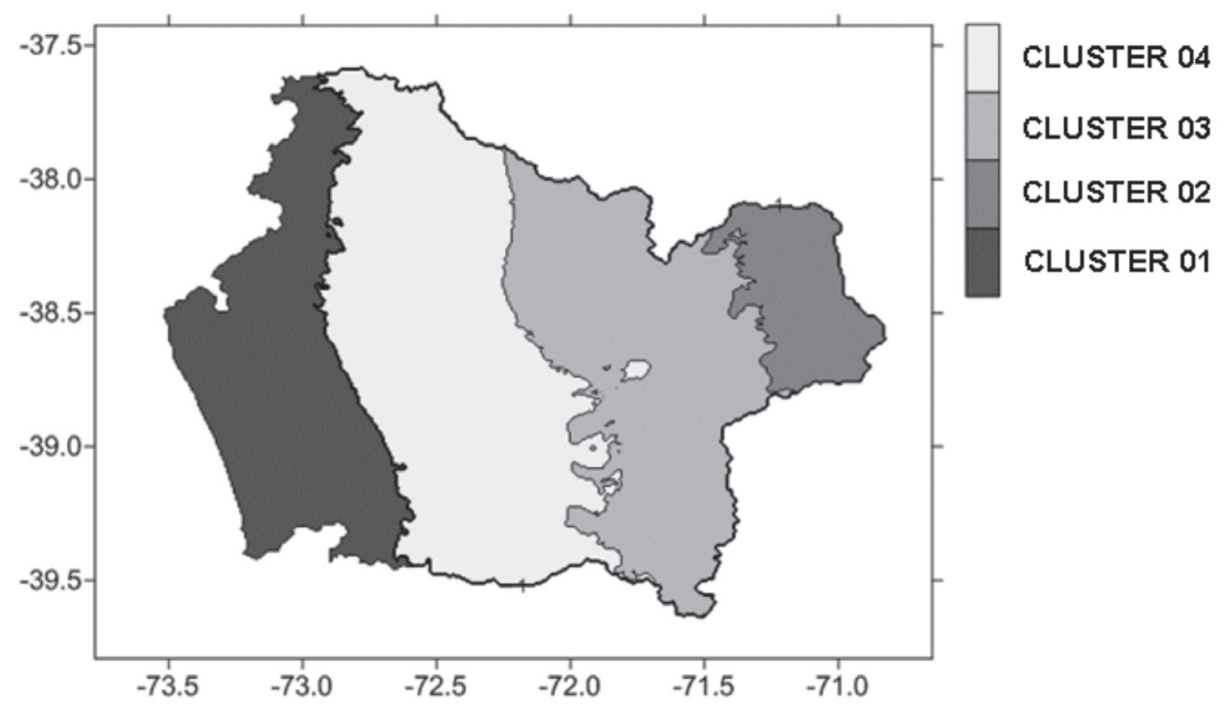

Figure 3. Cluster behaviour zones for precipitable water in the Araucanía Region, Chile.

The result of the cluster analysis in the study area shows that precipitable water vapour follows spacetime trends defined at a mean monthly level, which are very similar to the Köppen climate classification system. This fact is based on the observed dependence on geographical position, altitude and, in the case of this study area, distance from the coast. The same descriptors are used to model the spatial distribution of the climate in the study area, with satisfactory results (Díaz et al, 2010). In the study area, water vapour is transported primarily from the Pacific Ocean (Morales et al, 2009).
Table 2 shows the statistics describing each cluster in monthly values, with columns for the average (AVG), the Range $\left(\mathrm{W}_{\max }-\mathrm{W}_{\text {min }}\right)(\mathrm{RAN})$, and the coefficient of variation in percentage $(\mathrm{CV})$ of the precipitable water for each cluster in the time period considered.

Figure 4 shows the behaviour of the precipitable water for each cluster in the study area. In general terms, all the curves follow a similar comportment over time, with maximum values concentrated between January and March. This coincides with maximum solar radiation at median latitudes in the southern hemisphere, and therefore with a considerable increase in evaporation from the Pacific Ocean. 
In addition, it can be seen that the cluster with the greatest precipitable water is cluster 1 , the coastal zone, while the clusters with intermediate values are the central depression and the pre-cordillera. Cluster
2 equates to the zone with the lowest precipitable water content, corresponding to the Andes range in the Araucanía Region.

Table 2. Average monthly values (AVG), range (RAN) and coefficient of variation in percentage (CV) of PW for each cluster in the period 1989-2010.

\begin{tabular}{lcccccccccccc}
\hline Cluster & & $\mathbf{1}$ & \multicolumn{1}{c}{$\mathbf{2}$} & \multicolumn{3}{c}{$\mathbf{3}$} & & & $\mathbf{4}$ \\
\hline Statistics & AVG & RAN & CV & AVG & RAN & CV & AVG & RAN & CV & AVG & RAN & CV \\
\hline JAN & 1.493 & 0.124 & 2.238 & 1.113 & 0.070 & 1.380 & 1.240 & 0.123 & 2.407 & 1.358 & 0.128 & 2.699 \\
FEB & 1.524 & 0.121 & 2.080 & 1.175 & 0.070 & 1.214 & 1.291 & 0.129 & 2.065 & 1.398 & 0.124 & 2.386 \\
MAR & 1.533 & 0.133 & 2.298 & 1.140 & 0.076 & 1.392 & 1.271 & 0.138 & 2.391 & 1.392 & 0.136 & 2.724 \\
APR & 1.384 & 0.136 & 2.655 & 0.967 & 0.077 & 1.734 & 1.107 & 0.134 & 2.957 & 1.236 & 0.139 & 3.220 \\
MAY & 1.338 & 0.139 & 2.772 & 0.917 & 0.079 & 1.846 & 1.057 & 0.138 & 3.121 & 1.187 & 0.141 & 3.399 \\
JUN & 1.265 & 0.134 & 2.833 & 0.856 & 0.076 & 1.936 & 0.993 & 0.133 & 3.254 & 1.120 & 0.139 & 3.499 \\
JUL & 1.121 & 0.122 & 2.915 & 0.749 & 0.069 & 2.014 & 0.873 & 0.121 & 3.367 & 0.989 & 0.126 & 3.609 \\
AUG & 1.129 & 0.120 & 2.861 & 0.762 & 0.068 & 1.938 & 0.885 & 0.119 & 3.274 & 0.999 & 0.124 & 3.514 \\
SEP & 1.089 & 0.107 & 2.651 & 0.763 & 0.061 & 1.727 & 0.872 & 0.105 & 2.934 & 0.973 & 0.109 & 3.209 \\
OCT & 1.179 & 0.106 & 2.412 & 0.855 & 0.060 & 1.532 & 0.964 & 0.105 & 2.649 & 1.065 & 0.109 & 2.905 \\
NOV & 1.305 & 0.112 & 2.293 & 0.962 & 0.064 & 1.456 & 1.077 & 0.113 & 2.524 & 1.184 & 0.120 & 2.770 \\
DEC & 1.456 & 0.122 & 2.247 & 1.081 & 0.070 & 1.423 & 1.206 & 0.124 & 2.449 & 1.324 & 0.132 & 2.708 \\
\hline
\end{tabular}

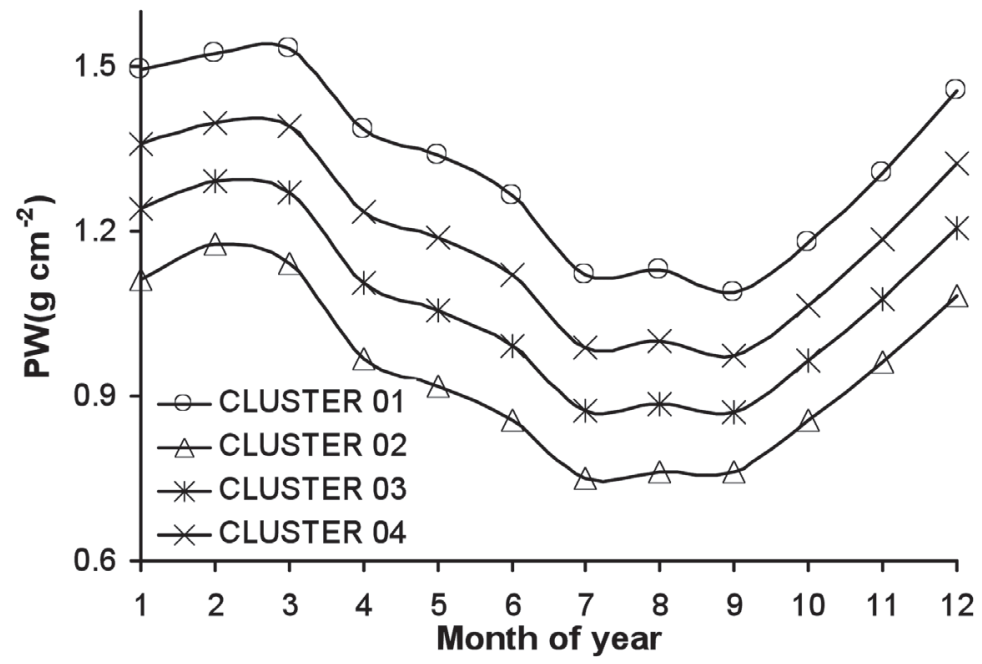

Figure 4. Variability over time in the monthly mean PW, period 1948-2005. 


\section{Conclusions}

A linear algorithm relating precipitable water to altitude and distance from the coast makes it possible to estimate and describe the space-time variability of precipitable water. This study, done on a regional scale, produced a statistical significance between the two variables of $p<0.01$, indicating that the relation is statistically significant, with confidence level $99 \%$.

A non-hierarchical cluster analysis, applied to the values for precipitable water, allowed the Araucanía Region to be stratified into different uniform zones, with the highest values of $\mathrm{W}$ found in the coastal zone, intermediate values in the central depression and pre-cordillera, and the lowest in the Andes range.

The proposed model offers an operational solution for obtaining PW information as a monthly mean when no daily information from radio soundings or satellite platforms is available. This provides an entry variable on which to base atmospheric corrections to thermal images, e.g. those supplied by the NOAA and TERRA platforms. This allows for applications in agricultural sciences when there is a need to estimate particular biophysical variables, such as thermal inertia and evapotranspiration, which appear to be closely linked to soil surface temperature.

\section{Acknowledgements}

J.C. Parra and L. Morales are grateful for financial support from project DI11-0033 of La Frontera University. J.C. Parra acknowledges Grant CONICYT PFB08-024.

\section{References}

American Geophysical Union (AGU). 2002. Water vapor in the climate system. Florida Ave., N.W., Washington DC 20009.
Dee D.P., S.M. Uppala, A. J. Simmons, P. Berrisford, P. Poli, S. Kobayashi, U. Andrae, M.A. Balmaseda, G. Balsamo, P. Bauer, P. Bechtold, A.C.M. Beljaar, L. van de Berg, J. Bidlot, N. Bormann, C. Delsol, R. Dragani, M. Fuentes, A.J. Geer, L. Haimberger, S.B. Healy, H. Hersbach, E.V. Holm, L. Isaksen, P. Kallberg, M. Kohler, M. Matricardi, A.P. McNally, B.M. Monge-Sanz, J.-J. Morcrette, B.-K. Park, C. Peubey, P. de Rosnay, C. Tavolato, J.-N. Thépaut, and F. Vitart. 2011. The Era interim reanalysis: configuration and performance of the data assimilation system. Q. J. R. Meteorol. Soc. $137,553-597$.

Díaz M. Diego, Luis Morales S., Giorgio Castellaro G., and Fernando Neira R. 2010. Topoclimatic modeling of thermopluviometric variables for the Bío-Bío and La Araucanía Regions, Chile. Chilean Journal of Agricultural Research, 70(4), p. 604-615.

Fuentes, U., D. Heimann. 2000. An improved statistical-dynamical downscaling scheme and its application to the Alpine precipitation climatology. Theor. Appl. Climatol. 65, 119-135.

Hadjimitsis, D., Z. Mitraka, I. Gazani2, A. Retalis, N. Chrysoulakis, and S. Michaelides. 2011. Estimation of spatio-temporal distribution of precipitable water using MODIS and AVHRR data: a case study for Cyprus. Adv. Geosci., 30, 23-29.

Morales, L., J.C. Parra, and J.A. Sobrino. 2002. Estimating land surface temperature in South America from NOAA-AVHRR images and reanalysis data. p. 698-707. Proc. First International Symposium on Recent Advances in Quantitative Remote Sensing. 16-20 September. Universidad de Valencia, Valencia, España.

Morales L. y J. C. Parra. 2002. Estimación de la radiancia emitida por la atmósfera en el infrarrojo térmico usando datos del reanálisis. Revista Mexicana de Física, Vol. 48 S3, pp. 119-121. 
Morales L., C.Mattar, L. Da-Silva and R. Abarca. 2009. Water vapour trends at several tropospheric levels over South America between 1973 and 2003. Il Nuovo Cimento, vol. 124 B, $\mathrm{N}^{\circ} 8$, pp 869-883.

Parra J.C., J.A. Sobrino, L. Morales, G. Castellano, J. Uribe, 2006. Application of a Split-Window Algorithm to estimate land surface temperature from AVHRR-NOAA data. Chilean J. Agric. Res., Vol. 66, Nro. 4, p. 385-392.

Parwati S., Totok S., Hasnaeni. 2007. Based on MODIS precipitable water for supporting spatial information over Java Island. Remote Sensing and earth Sciences, 4: 33-45.
Pérez, C. 2004. Técnicas de análisis multivariante de datos, (Ed. Pearson S.A. Madrid, España, 2004).

Wan Z. 1999. MODIS Land-Surface Temperature Algorithm Theoretical Basis Document, Institute for Computational Earth System Science University of California, Santa Barbara. Santa Barbara, CA, 93106-3060.

Wetterhall, F., Halldin, S., Xu, C-Y. 2007. Seasonality properties of four statistical-downscaling methods in central Sweden Theor. Appl. Climatol., 2007, Vol 87/1-4, pp 123-137.

Vera L., J.C. Parra, L. Morales, C. Mattar y E. Jorquera, 2010. Comparative analysis of Split-Window algorithms for estimating soil temperature. R.C. Suelo Nutr. Veg. 10(1): 35-39. 